\title{
Effect of Different Kinetic Factors on the Thermochemistry of Sulfophosphoric Attack Reaction of Natural Phosphate Tunisian by DRC
}

\author{
Olfa Lachkar-Zamouri ${ }^{*}$, Khemaies Brahim¹, Faten Bennour ${ }^{2}$, Ismail Khattech ${ }^{1}$ \\ ${ }^{1}$ Chemistry Department: LR15ES01 Materials, Cristallochemistry and Applied Thermodynamics Laboratory, \\ Faculty of Science, Tunis El Manar University, Tunis, Tunisia \\ ${ }^{2}$ Direction of Scientific Research, Tunisian Chemical Group, Sfax, Tunisia \\ Email: *zamouri.olfa@hotmail.fr
}

How to cite this paper: Lachkar-Zamouri, O., Brahim, K., Bennour, F. and Khattech, I. (2018) Effect of Different Kinetic Factors on the Thermochemistry of Sulfophosphoric Attack Reaction of Natural Phosphate Tunisian by DRC. Advances in Materials Physics and Chemistry, 8, 429-440.

https://doi.org/10.4236/ampc.2018.811029

Received: October 22, 2018

Accepted: November 13, 2018

Published: November 16, 2018

Copyright (c) 2018 by authors and Scientific Research Publishing Inc. This work is licensed under the Creative Commons Attribution International License (CC BY 4.0).

http://creativecommons.org/licenses/by/4.0/

\begin{abstract}
Mixture of phosphoric and sulfuric acid solutions has been used to investigate the dissolution of natural phosphates (PN) by DRC. The effect of concentration, particle size and stirring speed reaction is examined. Thermochimique properties of each kinetic parameters reaction are determined. It was found that these parameters have a considerable effect on the thermochemical aspect of the attack reaction. It is known that the process of $\mathrm{PN}$ sulphophosphoric acid attack leads to the formation of dihydrate $\left(\mathrm{CaSO}_{4} \cdot 2 \mathrm{H}_{2} \mathrm{O}: \mathrm{DH}\right)$. The present work shows the precipitation of other residues their formula depends on factors studied. The increase in concentration leads to the formation of hemihydrate $\left(\mathrm{CaSO}_{4} \mathrm{v1} / 2 \mathrm{H}_{2} \mathrm{O}: \mathrm{HH}\right)$ beside $\mathrm{DH}$ for the low values of $\%$ $\mathrm{H}_{2} \mathrm{SO}_{4}$ due to the solubility of dihydrate on the etching solution and the precipitation of $\left(\mathrm{Ca}\left(\mathrm{H}_{2} \mathrm{PO}_{4}\right)_{2} \cdot 2 \mathrm{H}_{2} \mathrm{O}\right)$ next of $\mathrm{DH}$ for low agitation values because of the lack of turbulence between the liquid phase and the solid phase which favors the precipitation of this latter compound.
\end{abstract}

\section{Keywords}

Thermochimique, Phosphate Ore, Differential Reaction Calorimetry, Concentration, String Speed, Particle Size

\section{Introduction}

The production of phosphoric acid is based on the attack of natural phosphates by the mixture of phosphoric and sulfuric acid. These acids are introduced simultaneously or successively [1]. The composition of natural phosphate (PN) varies from one source to another. Most of the world's phosphate rocks are of 
sedimentary origin and primarily derive from fluorapatite (FAP) by various substitutions [2] [3]. Therefore, these phosphates from different sources are expected to behave differently in acidulation processes. The process of phosphate ores dissolution occurring inside an industrial reactor is not yet quite clear. Therefore, several publications were conducted to studies the dissolution of phosphate synthetic [3]-[11] or natural [12]-[22] in aqueous acid solutions to clarify the kinetics and the process mechanism to improve the performance of phosphate attack. However, phosphate rocks decomposition by sulfuric acid remains the most widely used method and over $90 \%$ of the phosphoric acid produced worldwide is manufactured by digestion of phosphate rocks with sulfuric acid as an acidulant [21]. Dissolution of phosphate ore using sulfuric acid was examined by many researchers [23]-[30]. Sevim et al. [23] investigated the dissolution of phosphate ore in aqueous sulfuric acid. An Avrami-type equation was used successfully to explain kinetic data and the activation energy was determined as $29.66 \mathrm{~kJ} \cdot \mathrm{mol}^{-1}$. Olanipekun et al. [20] in the range of $60^{\circ} \mathrm{C}-90^{\circ} \mathrm{C}$ showed that the diffusion through an ash (or product) layer is the controlling step, and the activation energy of the dissolution of Nigerian phosphorite in aqueous solutions of sulfuric acid was determined as $17.60 \mathrm{~kJ} \cdot \mathrm{mol}^{-1}$. A similar conclusion has been obtained for the Nigerian phosphorite in a mixture of sulfuric and hydrochloric acids with activation energy as $13.25 \mathrm{~kJ} \cdot \mathrm{mol}^{-1}[19]$.

In spite of the multitude of reactive dissolutions, the majority of the published articles devoted to the kinetic study of the reaction of acid attack of the phosphates. The latter is a heterogeneous process with several phases. Fewer studies have been devoted to the thermodynamic study of the kinetic factors influencing the attack reaction, for which most of the time the studies the parameters are the initial concentrations of reagent and the temperature [4] [5] [7] [8] [12], the implementation is much more delicate such as the hydrodynamic parameters, the stirring speed, capable of modifying the mass transfer and makes it possible to promote the contacting of the reagents and thus to accelerate the reaction.

Similarly, the most widely used techniques in the literature are ICP [31], isoperibolic calorimetry [32] and microscopy [33]. These techniques do not allow precise tracking of the natural phosphate attack process. Other techniques provide more precise information on what happens in situ, such as microcalorimetry and Differential Reaction Calorimetry (DRC) [3]-[9] [12] [13] [16], which are not widely used, especially for kinetic studies. In fact, only a few works of our team have used these techniques. Brahim et al. [4] [5] used a C-80 SETARAM calorimeter to study the kinetic and thermodynamic aspects of the dissolution of a synthetic FAP in phosphoric acid at different concentrations $(10 \%, 18 \%$ and $30 \%$ by weight of $\mathrm{P}_{2} \mathrm{O}_{5}$ ) and hydrochloric acid [6]. A similar calorimeter has been utilized by Antar et al. [7] [8] to investigate the attack of a Fap by a mixture of phosphoric acid and sulfuric acids at different temperatures. Antar and Jemal [12] determined three processes for the digestion, of phosphate ore in a mixture of phosphoric and sulfuric acid, at $25^{\circ} \mathrm{C}$ which are dissolution of the ore, preci- 
pitation of calcium sulfate hemihydrate and transformation of the latter into dihydrate. In another work performed on a synthetic carbonate fluorapatite $\left(\mathrm{CO}_{3}\right.$-Fap) in phosphoric acid at $25^{\circ} \mathrm{C}-55^{\circ} \mathrm{C}$, Zendah et al. [9] found that the dissolution is controlled by a diffusion phenomenon. Of the same, Amira et al. [13] [16] study the kinetics of attack of a Tunisian phosphate ore with $25 \%$ by weight of $\mathrm{P}_{2} \mathrm{O}_{5}$ phosphoric acid in the range of $25^{\circ} \mathrm{C}$ to $65^{\circ} \mathrm{C}$ with a DRC. This calorimetry has been launched by SETARAM and developed by Aventis Pharma in their own laboratories to optimize the industrial processes and the safety of chemical reactions. DRC gives fast access to thermodynamic data, such as reaction heat, heat flow and heat capacity.

In a previous work [22], we studied the effect of the solid/liquid ratio and the temperature on the thermodynamic aspect of the sulfophosphoric attack reaction of a natural phosphate using a SETARAM calorimeter by differential reaction calorimetry (DRC). The process leads to the formation of a compound whose formula depends on the solid/liquid ratio. The gradual increase of this ratio leads to the formation of hemihydrate $\left(\mathrm{CaSO}_{4} \cdot 1 / 2 \mathrm{H}_{2} \mathrm{O}: \mathrm{HH}\right)$, dihydrate ( $\mathrm{Ca}$ $\left.\mathrm{SO}_{4} \cdot 2 \mathrm{H}_{2} \mathrm{O}: \mathrm{DH}\right)$ or a mixture of these two products. The effect of temperature on the dissolution of NP in the sulfophosphoric mixture shows that the variation of the heat quantity $\Delta \mathrm{H}_{\text {mes }}$, calculated by integration of the raw signal, as a function of the temperature in the range of $25^{\circ} \mathrm{C}$ to $65^{\circ} \mathrm{C}$ near temperature. This behavior was attributed to a modification of the reaction mechanism on both sides of this temperature. It was interesting to determine how the thermochemistry of the PN sulfophosphoric attack reaction varies with other kinetic factors such as acid concentration, agitation rate and particle size. This article deals with the variation of these last factors on the dissolution of PN in the acid mixture.

\section{Material and Method}

Phosphate rocks were obtained from a mine located in Gafsa (Tunisia). It was supplied by the manufacture CPG (Company of Phosphate from Gafsa). The chemical composition determined by thermogravimetry using a B60 SETARAM microbalance, ionometry using a specific fluoride electrode ISE25F and $\mathrm{Ag} / \mathrm{AgCl}$ reference electrode and inductively coupled plasma (ICP) [16].

The DRC used is a SETARAM model which works based on the simple principle of differential thermal analysis which continuously measures a temperature difference, $\Delta \mathrm{T}$, between a measuring reactor and a reference one. The infallibility of this apparatus for kinetic and thermodynamic studies has been thoroughly researched by Amira et al. [34]. The experimental protocol followed to study the dissolution of the $\mathrm{PN}$ in the mixture of sulfuric and phosphoric acid solution can be described as follows: $100 \mathrm{~g}$ of the attacking solution, $\mathrm{S},(20 \mathrm{~g}$ of concentrated sulfuric acid and $80 \mathrm{~g}$ of recycled phosphoric acid, $20 \%$ of $\mathrm{P}_{2} \mathrm{O}_{5}$ ) and a mass " $\mathrm{m}$ " of the PN in a sealed sample holder which prevents its contact with the attacking solution were placed in the measuring reactor. To keep things balanced, the same amount of reactants was placed in the reference reactor. The contact of the 
two reagents is triggered by opening the sample holder. Some time, which varies according to the kinetics of the phenomenon, is necessary to regain thermal equilibrium which is seen by the return to the baseline. A calibration operation is then carried out by recreating in the measuring cell a power close to that produced by the chemical phenomenon studied for a variable period of time. The same calibration operation is also performed before the NP attack. These two operations are essential to establish the specific heat of the mixture obtained before and after dissolving the PN.

\section{Results and Discussion}

\subsection{Thermochemical Effect of PN Composition}

The same initial conditions were used for all the experiments carried out in this section: $100 \mathrm{~g}$ of a sulfo-phosphoric mixture containing $80 \mathrm{~g}$ of recycled phosphoric acid, $20 \%$ of $\mathrm{P}_{2} \mathrm{O}_{5}$ and $20 \mathrm{~g}$ of sulfuric acid at $98 \%$ of $\mathrm{H}_{2} \mathrm{SO}_{4}$. To this, $25 \mathrm{~g}$ of NP of a well-defined grain size are added. The stirring and the temperature are set to $200 \mathrm{rpm}$ and $25^{\circ} \mathrm{C}$, respectively. The precipitate obtained at the end of each manipulation does not contain, among other things, non-attacked NP (Figure 1).

It is well known that grain size only has an effect on the kinetic aspect of the attack reaction [13]-[19]. However, as will be seen; our results reveal that it also has a considerable effect on the thermochemical aspect. Indeed, the mass enthalpy measured for the different grain sizes (100, 160, 200, 315 and $500 \mu \mathrm{m}$ ) undergoes a very significant change for a temperature of $25^{\circ} \mathrm{C}$ (Figure 2). This result seems to be surprising. Thus, to explain this behavior, the composition of $\mathrm{P}_{2} \mathrm{O}_{5}$ (Figure 3) and that of calcium carbonate (Figure 4) were used for each grain size. For this reason, the $\mathrm{P}_{2} \mathrm{O}_{5}$ content was determined by spectrophotometry according to the method described by Gee and Deitz [35]. Examination of the curve in Figure 3 shows that the composition of the different $\mathrm{P}_{2} \mathrm{O}_{5}$ sections has a random dispersion. A similar result was observed by Ben Brahim et al. [15].

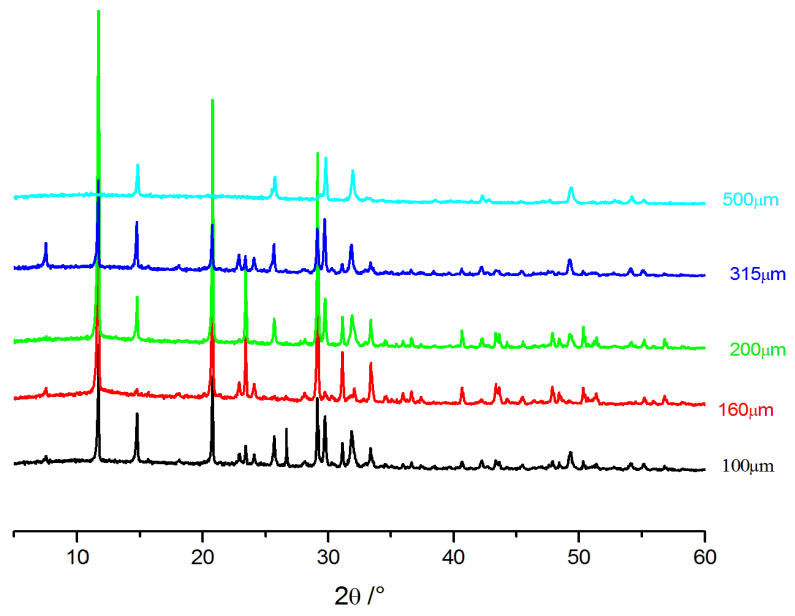

Figure 1. Diffractograms recorded for different NP particle sizes. 


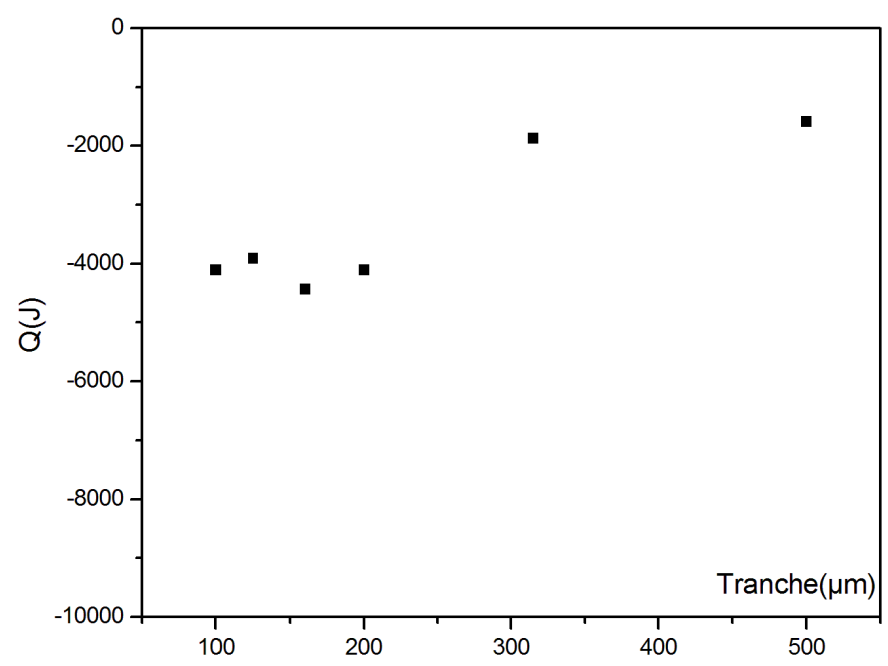

Figure 2. The change in heat, $\mathrm{Q}$, measured as a function of the NP particle size $(\mu \mathrm{m})$.

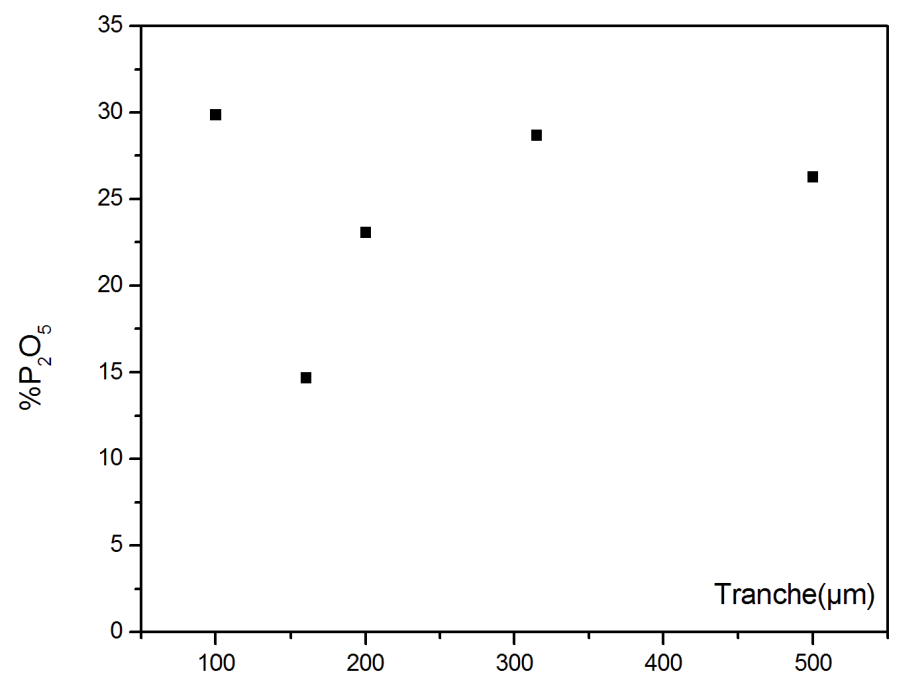

Figure 3. $\mathrm{P}_{2} \mathrm{O}_{5}$ percentage as a function of NP particle size.

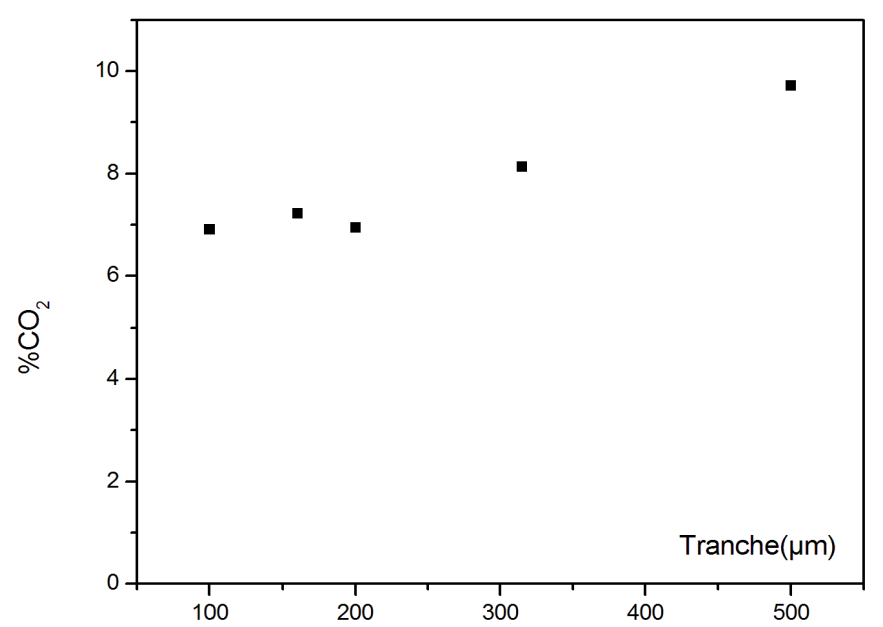

Figure 4. $\mathrm{CO}_{2}$ percentages as a function of the NP particle size $(\mu \mathrm{m})$. 
So the change in enthalpy appears to be related to the change in the chemical composition regarding the calcium carbonate. Indeed, the curves in Figures 2-4 have the same shape. This result is not surprising because Tunisian phosphate is known for its high reactivity due to its relatively high carbonate content.

\subsection{Thermochemical Effect of Stirring Rates}

Stirring and mixing are two complex homogenization operations involving hydrodynamic, thermal, chemical and mechanical phenomena. As will be seen in this work, these two operations not only affect the kinetics of the attack reaction but also the nature of the final products. Indeed, under industrial conditions, and by varying the stirring speed from 50 to $400 \mathrm{rpm}$, measurement of the heat, $\mathrm{Q}$, calculated by integrating the raw signal as a function of the stirring rate shows the presence of two sections (Figure 5). The first one, obtained for stirring rates lower than $150 \mathrm{rpm}$, shows a linear variation of heat. The second one shows that heat stays constant for higher stirring rates. This result is surprising. That is why an X-ray diffraction analysis was performed on the precipitates obtained after each experiment. Results show the formation of calcium phosphate dihydrate $\left(\mathrm{Ca}\left(\mathrm{H}_{2} \mathrm{PO}_{4}\right)_{2} \cdot 2 \mathrm{H}_{2} \mathrm{O}\right)$ with phosphogypsum $\left(\mathrm{CaSO}_{4}, 2 \mathrm{H}_{2} \mathrm{O}\right)$ in the first section (Figure 6(a)), and the precipitation of only phosphogypsum in the second section (Figure 6(b)). However, this on its own does not explain the change in heat as a function of stirring rate. Thus, in order to interpret the shape of the curve obtained, the amount of syncrystallized $\mathrm{P}_{2} \mathrm{O}_{5}$ was determined. The results obtained show that the amount of syncrystallized $\mathrm{P}_{2} \mathrm{O}_{5}$ decreases as the stirring rate increases and then becomes constant at around $150 \mathrm{rpm}$ (Figure 7).

Therefore, taking into account the precipitation enthalpy of monocalcium phosphate $\left(\Delta_{\text {pre }} \mathrm{H}=-5.2 \mathrm{~kJ} \cdot \mathrm{mol}^{-1}\right)$ on one hand [36] [37], and that of $\mathrm{DH}$ [38] on the other hand, the total heat, $\mathrm{Q}_{\mathrm{tot}}$, released during the sulfo-phosphoric attack

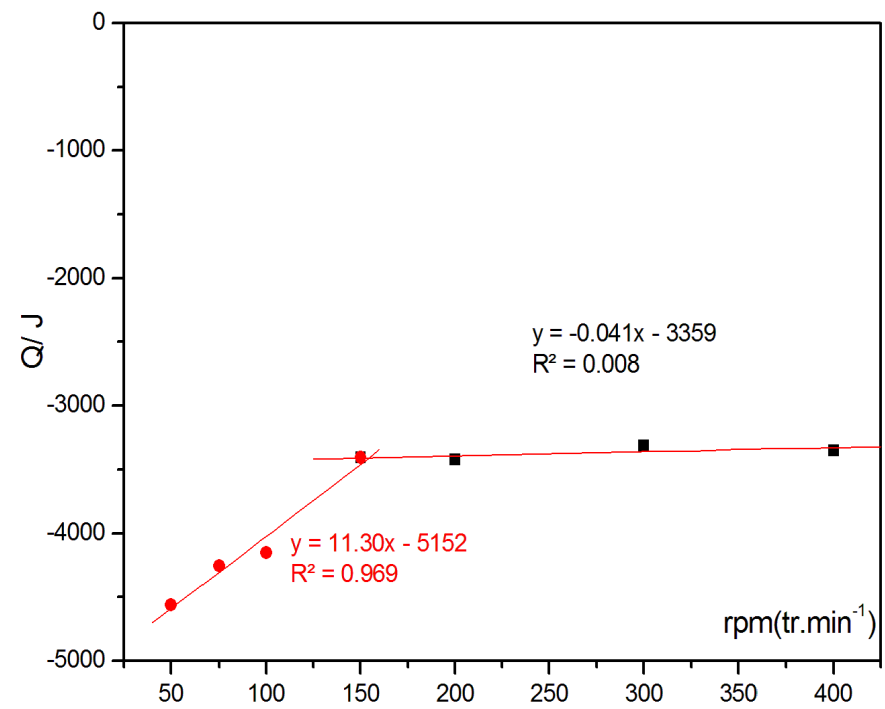

Figure 5. The change in energy, $Q$, as a function of stirring rate. 


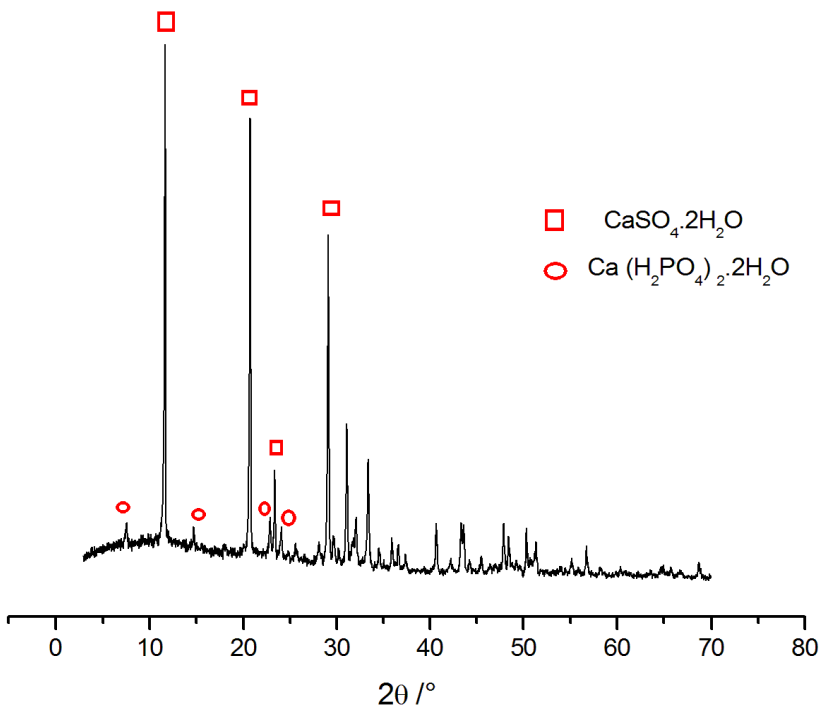

(a)

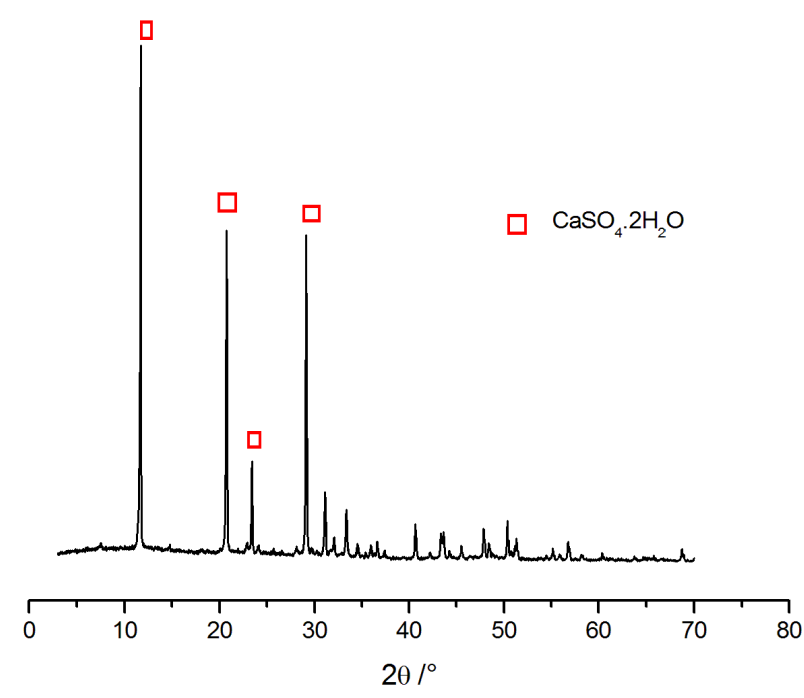

(b)

Figure 6. Diffractograms recorded for different stirring rates (a) $50 \mathrm{rpm}$; (b) $400 \mathrm{rpm}$.

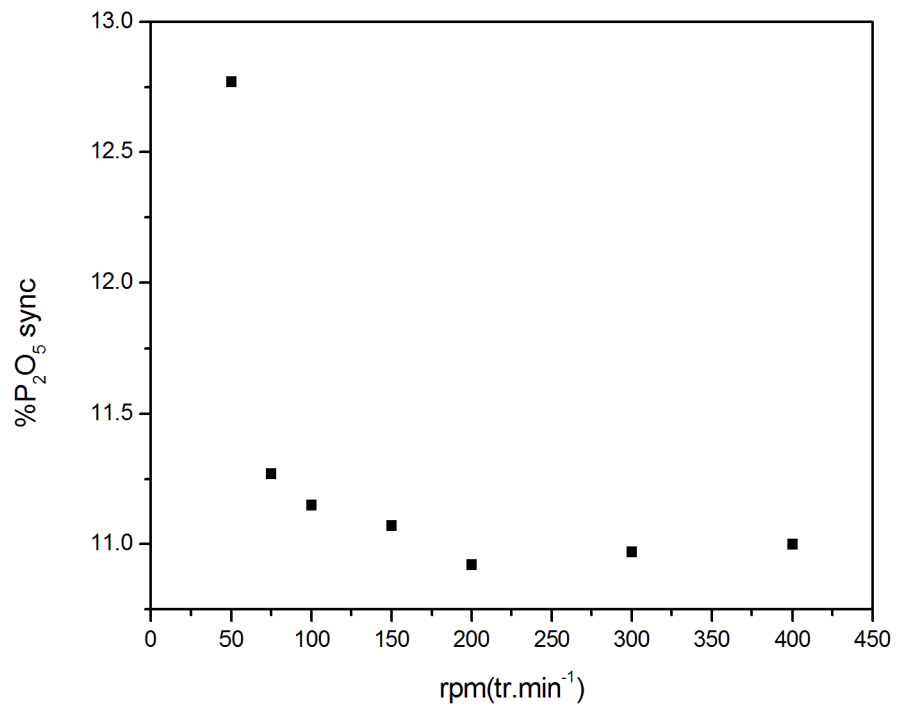

Figure 7. Percentage of syncrystallized $\mathrm{P}_{2} \mathrm{O}_{5}$ as a function of stirring rate.

on the NP can be written as a function of the heats " $\mathrm{Q}_{1}$ " and " $\mathrm{Q}_{2}$ " that result from the precipitation of monocalcium phosphate and $\mathrm{DH}$, respectively: $\mathrm{Q}_{\text {tot }}=$ $\mathrm{Q}_{\text {diss }}+\mathrm{Q}_{1}+\mathrm{Q}_{2}$ where $\mathrm{Q}_{\text {diss }}$ is the heat released by the dissolution of NP. Thus, in the first section, $\mathrm{Q}_{1}$ decreases and $\mathrm{Q}_{2}$ increases. This explains the positive sign of the slope of the line segment obtained in the first section. However, the heat measured in the second section and written as $Q_{\text {glob }}=Q_{\text {diss }}+Q_{2}$ is constant.

\subsection{Thermodynamic Effect of Sulfuric Acid Concentration}

The attack reaction on the phosphates with an acid solution is a heterogeneous reaction. It is evident that concentration plays a very important role in the 


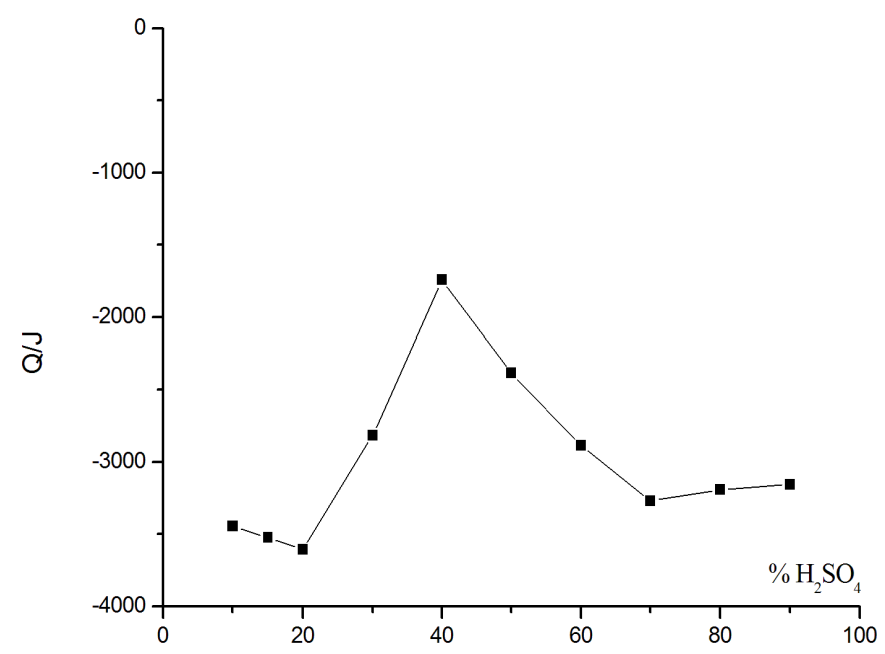

Figure 8. Total enthalpy as a function of sulfuric acid concentration.

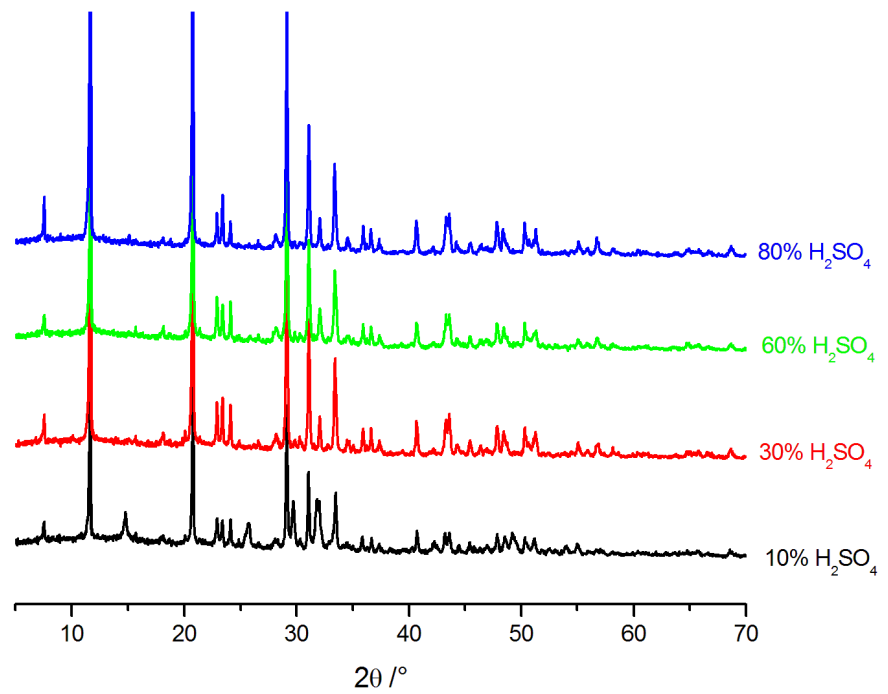

Figure 9. Diffractograms recorded for different sulfuric acid concentrations.

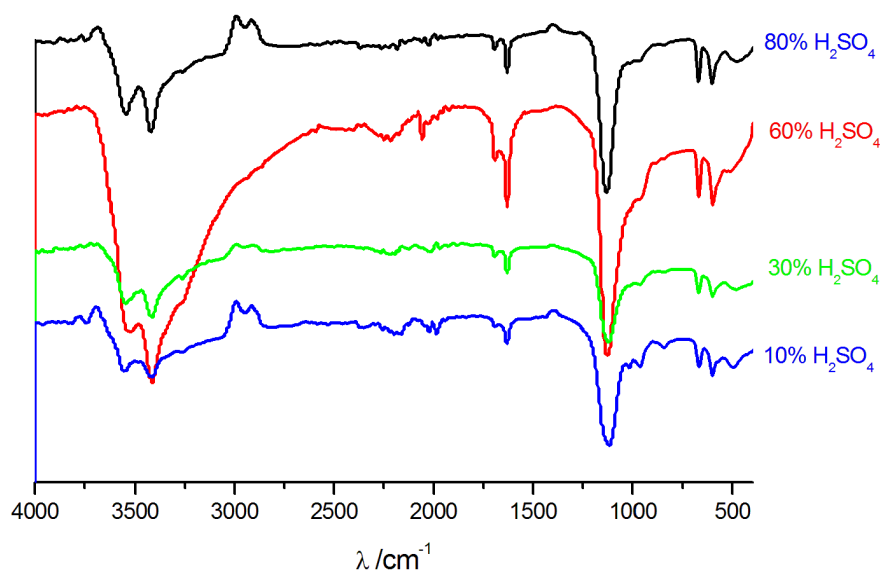

Figure 10. The IR spectra recorded for different sulfuric acid concentrations. 
kinetics of this reaction. For this reason several dissolutions of the sulfophosphoric mixture acids were carried out by progressively increasing the concentration of sulfuric acid while keeping all other quantities constant. The concentration was varied from $10 \%$ to $98 \%$ by mass of $\mathrm{H}_{2} \mathrm{SO}_{4}$. As will be shown hereunder, this does not only affect the heat measured, but also the nature of the products formed. Indeed, the plot of heat, $Q$, as a function of the concentration of sulfuric acid suggests the presence of four different sections (Figure 8). However, the analysis of the residues obtained after each attack shows the presence of two zones, each corresponding to a particular concentration range of $\mathrm{H}_{2} \mathrm{SO}_{4}$, denoted as $\mathrm{C}_{1}$ and $\mathrm{C}_{2}$, respectively.

In the first zone defined for low sulfuric acid concentrations $\left(\left[\mathrm{H}_{2} \mathrm{SO}_{4}\right] \leq 20 \%\right)$, the XRD (Figure 9) and IR (Figure 10) studies of the residue show a mixture of $\mathrm{HH}$ and DH. In the second zone, the dissolution leads to the precipitation of only DH. In order to interpret the thermochemical behavior of the dissolution of the NP in the first zone, the behavior of the energy was studied for the DH formation reaction from $\mathrm{HH}$. The value of the molar enthalpy of this transformation, $\Delta_{\mathrm{r}} \mathrm{H}^{\circ}=-17 \mathrm{~kJ} \cdot \mathrm{mol}^{-1}$ [38] explains the negative sign of the slope of the line segment obtained in this zone. However, the change in heat in the second zone appears to be essentially related to the solubility of $\mathrm{DH}$. Indeed, the shape of the curve obtained in this study is identical to that found by Wehde and Stichlmair when studying the change in solubility of $\mathrm{DH}$ as a function of the concentration of $\mathrm{H}_{2} \mathrm{SO}_{4}$ [39].

\section{Conclusion}

The thermochemical study of sulfophosphoric attack of Tunisian phosphate ore was investigated calorimetrically, considering the effect of grain size, string rate and concentration on the attack reaction. Attack of a phosphate ore by mixture acid solution is a complex process probably beginning by dissolution of the ore and then precipitation of calcium compounds their formula depends on factors studied. These kinetic parameters not only have effect in the kinetics of the attack reaction but also have a considerable effect on the thermochemical aspect. We will not stop at the stage of the thermodynamic study of the sulfophosphoric attack reaction. Our approach in the future work is to study the kinetic aspect of this last reaction by varying the different kinetic factors influencing the reaction attack.

\section{Conflicts of Interest}

The authors declare no conflicts of interest regarding the publication of this paper.

\section{References}

[1] Becker, P. (1989) Phosphates and Phosphoric Acid. Marcel Dekker.

[2] Hsieh, S.S. (1987) Beneficiation of Dolomitic Phosphate Ores Using Modified Cra- 
go-TVA Process. Industrial \& Engineering Chemistry Research, 26, 1413-1419. https://doi.org/10.1021/ie00067a024

[3] Chihi, H., Khattech, I. and Jemal, M. (2016) Preparation, Characterization and Thermochemistry of Magnesium Carbonate Co-Substituted Fluorapatites. Journal of Thermal Analysis and Calorimetry, 127, 2427-2438. https://doi.org/10.1007/s10973-016-5693-2

[4] Brahim, K., Antar, K., Khattech, I. and Jemal, M. (2008) Effect of Temperature on the Attack of Fluorapatite by a Phosphoric Acid Solution. Scientific Research and Essays, 3, 35-39.

[5] Brahim, K., Khattech, I., Dubés, J.P. and Jemal, M. (2005) Etude cinétique et thermodynamique de la dissolution de la fluorapatite dans l'acide phosphorique. Thermochimica Acta, 436, 43-50. https://doi.org/10.1016/j.tca.2005.06.019

[6] Brahim, K., Baatout, A.S., Khattech, I. and Jemal, M. (2017) Dissolution Kinetics of Fluorapatite in the Hydrochloric Acid Solution. Journal of Thermal Analysis and Calorimetry, 129, 701-708. https://doi.org/10.1007/s10973-017-6221-8

[7] Antar, K., Brahim, K. and Jemal, M. (2006) Étude cinétique et thermodynamique de l'attaque d'une fluorapatite par des mélanges d'acides sulfurique et phosphorique À $25^{\circ}$ C. Thermochimica Acta, 449, 35-41. https://doi.org/10.1016/j.tca.2006.07.011

[8] Antar, K. and Jemal, M. (2007) Kinetics and Thermodynamics of the Attack of Fluorapatite by a Mixture of Sulfuric and Phosphoric Acids at $55^{\circ} \mathrm{C}$. Thermochimica Acta, 452, 71-75. https://doi.org/10.1016/j.tca.2006.09.019

[9] Zendah, H., Khattech, I. and Jemal, M. (2013) Thermochemical and Kinetic Studies of the Acid Attack of "B" Type Carbonate Fluorapatites at Different Temperatures (25-55) ${ }^{\circ}$ C. Thermochimica Acta, 565, 46-51. https://doi.org/10.1016/j.tca.2013.04.033

[10] Guidry, M.W. and Mackenzie, F.T. (2003) Experimental Study of Igneous and Sedimentary Apatite Dissolution: Control of $\mathrm{pH}$, Distance from Equilibrium, and Temperature on Dissolution Rates. Geochimica et Cosmochimica Acta, 67, 2949-2963. https://doi.org/10.1016/S0016-7037(03)00265-5

[11] Dorozhkin, S.V. (1997) Surface Reactions of Apatite Dissolution. Journal of Colloid and Interface Science, 191, 489-497. https://doi.org/10.1006/jcis.1997.4942

[12] Antar, K. and Jemal, M. (2008) Kinetics and Thermodynamics of the Attack of a Phosphate Ore by Acid Solutions at Different Temperatures. Thermochim Acta, 474, 32-35. https://doi.org/10.1016/j.tca.2008.05.006

[13] Amira, B.S., Brahim, K., Khattech, I., Kamoun, L. and Jemal, M. (2016) Thermochemical and Kinetic Investigations of the Phosphoric Attack of Tunisian Phosphate Ore. Journal of Thermal Analysis and Calorimetry, 131, 3121-3132. https://doi.org/10.1007/s10973-017-6825-Z

[14] Chaabouni, A., Chtara, C., Nzihou, A. and El-Feki, H. (2013) Kinetic Study of the Dissolution of Tunisian Natural Phosphate or Francolite in Industrial Phosphoric Journal of Advances in Chemistry, 6, 908-916. https://doi.org/10.24297/jac.v6i1.6585

[15] Ben Brahim, F., Mgaidi, M. and Elmaaoui, M. (1999) Kinetics of Leaching of Tunisian Phosphate Ore Particles in Dilute Phosphoric Acid Solutions. The Canadian Journal of Chemical Engineering, 77, 136-142. https://doi.org/10.1002/cjce.5450770123

[16] Amira, B.S., Ibrahim, K., Khattech, I. and Jemal, M. (2016) Attack of Tunisian Phosphate Ore by Phosphoric Acid Kinetic Study by Means of Differential Reaction Calorimetry. Journal of Thermal Analysis and Calorimetry, 124, 1671-1678. 
https://doi.org/10.1007/s10973-016-5263-7

[17] Ashraf, M., Iqbal Zafar, Z. and Ansari, T.M. (2005) Selective Leaching Kinetics and Upgrading of Low-Grade Calcareous Phosphate Rock in Succinic Acid. Hydrometallurgy, 80, 286-292. https://doi.org/10.1016/j.hydromet.2005.09.001

[18] Gharabaghi, M., Irannajad, M. and Noaparast, M. (2010) A Review of the Beneficiation of Calcareous Phosphate Ores Using Organic Acid Leaching. Hydrometallurgy, 103, 96-107. https://doi.org/10.1016/j.hydromet.2010.03.002

[19] Aly, H.F., Ali, M.M. and Taha, M.H. (2013) Dissolution Kinetics of Western Deseret Phosphate Rocks, Abu Tartur with Hydrochloric Acid. Arab Journal of Nuclear Science and Applications, 46, 1-16.

[20] Olenipekun, E.O. (1999) Kinetics of Dissolution of Phosphorite in Acid Mixtures. Bulletin of the Chemical Society of Ethiopia, 13, 63-70. https://doi.org/10.4314/bcse.v13i1.21057

[21] Sınırkaya, M., Özerand, A.K. and Gülaboğlu, M.Ş. (2014) Investigation of Solubilities of Sulfated and Ground Phosphate Rock after Sulfation in $\mathrm{H}_{2} \mathrm{SO}_{4}$ Solution. Pamukkale Üniversitesi Mühendislik Bilimleri Dergisi, 20, 253-257

[22] Olfa, L.Z., Khemaies, B., Feten, B.M. and Ismail, K. (2018) Attack of Tunisian Phosphate Ore by a Mixture of Sulfuric and Phosphoric Acid: Thermochemical Study by Means of Differential Reaction Calorimetry. Advances in Materials Physics and Chemistry, 8, 411-427. https://doi.org/10.4236/ampc.2018.810028

[23] Sevim, F., Saraçand, H. and Yartasi, A. (2003) Dissolution Kinetics of Phosphate Ore in $\mathrm{H}_{2} \mathrm{SO}_{4}$ Solutions. Industrial and Engineering Chemistry Research, 42, 2052-2057.https://doi.org/10.1021/ie020168o

[24] Lassis, M., Mizane, A., Dadda, N. and Rehamnia, R. (2015) Dissolution of Djebel Onk Phosphate Ore Using Sulfuric Acid. Environmental Nanotechnology, Monitoring and Management, 4, 12-16.

[25] Mizane, A. and Louhi, A. (2008) Calcination Effects on Sulfuric Dissolution of Phosphate Extracted from Djebel Onk Mine (Algéria). Asian Journal of Chemistry, 20, 711-717.

[26] Fariss, T.F., Elnashaie, S.S.E.H., Abdel-Razik, S.M., Abdel-Aleem, F.A. and Ibrahim H.A. (1991) Comparison between Acidulation by Sulfuric Acid and by Phosphoric Acid for Saudi Phosphate Rock. Fertilizer Research, 29, 209-227. https://doi.org/10.1007/BF01048962

[27] Mizane, A. and Louhi, A. (2007) Comparative Study of the Dissolution of Phosphate Rock of Djebel Onk (Algeria) by the Nitric Acid and the Sulphuric Acid. Journal of Engineering and Applied Sciences, 2, 1016-1019.

[28] Gilbert, R.L. and Moreno, E.C. (1965) Dissolution of Phosphate Rock by Mixtures of Sulfuric and Phosphoric Acids. Industrial and Engineering Chemistry Process Design and Development, 4, 368-371.https://doi.org/10.1021/i260016a006

[29] Jamialahmadi, M. and Emam, S.H. (1998) Dissolution of Phosphate Rock by Mixtures of Sulfuric and Phosphoric Acid. Developments in Chemical Engineering and Mineral Processing, 6, 273-293. https://doi.org/10.1002/apj.5500060503

[30] Frikha, N., Hmerchaand, A. and Gabsi, S. (2014) Modelling of a Solid Dissolution in Liquid with Chemical Reaction: Application to the Attack Reaction of Phosphate by Sulphuric Acid. The Canadian Journal of Chemical Engineering, 92, 1829-1838. https://doi.org/10.1002/cjce.21986

[31] der Sluis, S.V., Meszaros, Y., Marchee, W.G.J., Wesselingh, H.A. and Van Rosmalen, G.M. (1987) The Digestion of Phosphate Ore in Phosphoric Acid. Industrial \& 
Engineering Chemistry Research, 26, 2501-2505.

https://doi.org/10.1021/ie00072a020

[32] Huffmann, E.O., Cate, W.E., Deming, M.E. and Elmore, K.L. (1957) Solubility of Phosphates, Rates of Solution of Calcium Phosphates in Phosphoric Acid Solutions. Journal of Agricultural and Food Chemistry, 5, 266-275. https://doi.org/10.1021/jf60074a001

[33] Dorozohkin, S.V. and Prakt, J. (1996) Dissolution Kinetics of Single Flourapatite Crystals in Phosphoric Acid Solution under the Conditions of the Wet-Process Phosphoric Acid Production. Journal für Praktische Chemie, 338, 620-626.

[34] Amira, B.S., Hichri, M., Bechrifa, A. and Khattech, I. (2014) Test and Calibration Processes for the Differential Reaction Calorimeter (DRC): Application: Dissolution of Calcium Fluorapatite in the Hydrochloric Acid. Thermochimica Acta, 580, 85-92. https://doi.org/10.1016/j.tca.2014.02.006

[35] Gee, A. and Deitz, V.R. (1953) Determination of Phosphate by Differential Spectrophotometry. Analytical Chemistry, 25, 1320-1324.

https://doi.org/10.1021/ac60081a006

[36] Elasri, S., Ben Cherifa, A., Bouhaouss, A., Ferhat, M. and Jemal, M. (1995) Dissolution Mechanism of $\beta$-Tricalcium Phosphate and Hydroxyapatite in Phosphoric Acid Solutions. Thermochimica Acta, 249, 121-126. https://doi.org/10.1016/0040-6031(95)90680-0

[37] Brahim, K., Antar, K., Khattech, I. and Jemal, M. (2006) Thermodynamic and Kinetic Study of the Attack of Fluoropatite by Phosphoric Acid Solutions. Annales de Chimie-Science des Matériaux, 31, 611-620. https://doi.org/10.3166/acsm.31.611-620

[38] Navrotsky, A. (2004) Energetic Clues to Pathways to Biomineralization: Precursors, Clusters, and Nanoparticles. Proceedings of the National Academy of Sciences of the United States of America, 101, 12096-12101. https://doi.org/10.1073/pnas.0404778101

[39] Wehde, K.-H. and Stichlmair, J. (1985) Solubility Behavior of Inorganic Sulfates in Sulfuric Acids of Various Concentrations. Chemie Ingenieur Technik, 57, 348-349. https://doi.org/10.1002/cite.330570418 